\title{
Characterization of Mesenchymal Stem Cells Derived from Rat Bone Marrow and Adipose Tissue: A Comparative Study
}

\author{
Ahmed Lotfy ${ }^{1,2}$, Mohamed Salama ${ }^{1}$, Faten Zahran $^{3}$, Elena Jones ${ }^{4}$, Ahmed Badawy ${ }^{1}$, Mohamed Sobh ${ }^{1}$ \\ ${ }^{1}$ Medical Experimental Research Center (MERC), Faculty of Medicine, Mansoura University, Mansoura, \\ ${ }^{2}$ Center of Excellence for Stem Cells and Regenerative Medicine (CESCRM), Zewail City of Science and Technology, \\ ${ }^{3}$ Biochemistry Department, Faculty of Science, Zagazig University, Egypt, \\ ${ }^{4}$ Leeds Institute of Rheumatic and Musculskeletal Medicine, University of Leeds, Leeds, UK
}

\begin{abstract}
Background and Objectives: Stem cell technology offers a new hope for many chronic disorders patients. The types of stem cells are different with many differences existing between each type. Mesenchymal stem cells (MSCs) represent one type of adult stem cells that can be easily isolated, then re-transplanted to the patients. This offers potential for their future application in treating many disorders without fear of rejection possibility. MSCs can be isolated from different sources e.g. bone marrow (BMSCs) and adipose tissue (ADSCs). In the present study we compared BMSCs and ADSCs isolated from Sprague-Dawley rats.

Methods and Results: For this comparison, immunophenotyping, the analysis of growth rates, proliferation by colony forming unit-fibroblast assay, population doubling time, and trilineage differentiation assays were performed for both BMSCs and ADSCs. The findings revealed that despite no difference in immunphenotypic character between BMSC and ADSC, a better proliferative capacity was observed for ADSCs which would advocate their better use in regenerative applications. On the other hand, BMSCs showed more potential for osteogenic and chondrogenic differentiation. Conclusions: Our study showed that, despite many similarities between both types of cells, there are differences existing which can offer assistance on choosing type of cell to be used in specific diseases. Although ADSCs seem more promising for regenerative application generally, BMSCs may represent a better choice for treating bone disorders.
\end{abstract}

Keywords: Mesenchymal Stem Cells, Bone Marrow, BMSCs, ADSCs, Characterization, Sprague-Dawley Rats

\section{Introduction}

There is no universally acceptable definition of the term

\footnotetext{
Accepted for publication October 8, 2014, Published online November 30, 2014 Correspondence to Ahmed Lotfy

Medical Experimental Research Center (MERC) Faculty of Medicine, Mansoura University, Center of Excellence for Stem Cells and Regenerative Medicine (CESCRM), Zewail City of Science and Technology, Egypt

Tel: +201005593149

E-mail: lotfy_bio@hotmail.com

(c) This is an open-access article distributed under the terms of the Creative Commons Attribution Non-Commercial License (http://creativecommons.org/ licenses/by-nc/3.0/), which permits unrestricted non-commercial use, distribution, and reproduction in any medium, provided the original work is
} properly cited.
"Stem cell". Many efforts have been made for defining certain characters which can differentiate stem cells from other cells encountered either in vivo or in cell cultures (1). One of the definitions accepted by many authors is that stem cells are unspecialized cells in the human body that are capable of becoming specialized cells, each with new specialized cell functions (2). The unique capabilities of stem cells for pluripotency and long-term self-renewal make them ideal source for the regeneration of injured tissue. Despite the numerous obstacles, the potential for cell-based therapy in the treatment of degenerative diseases of all organ systems, provides an exciting arena for continued research $(3,4)$. The multiple applications of stem cells; not only for regeneration but also in predictive toxicology, drug discovery and drug delivery studies de- 
note the importance of the field of stem cell technology $(5,6)$.

Mesenchymal stem cells (MSCs) are adult stem cells that possess self-renewal and multi-lineage differentiation potentials, and considered an attractive source of stem cells for tissue engineering (7-10). Previous pre-clinical studies have shown that MSCs from different sources, including human bone marrow (BMSCs), cord blood, embryo and fetal membranes can be applied in tissue repair, such as promoting recovery from acute kidney injury (AKI) induced by various causes $(11,12)$. Nonetheless, do the different sources of mesenchymal stem cells offer different characters of these cells? Although previous researches tried to answer this question, inconsistent findings were reported (13-17). In the current study we will compare in vitro characteristics of bone marrow mesenchymal stem cells (BMSCs) and adipose tissue mesenchymal stem cells (ADSCs) obtained from Sprague-Dawley rats.

\section{Materials and Methods}

\section{Isolation of Mesenchymal stem cells from rat bone marrow}

Isolation of MSCs from bone marrow (BM) was performed as previously described (18) with some modifications. Eight-week-old male Sprague-Dawley rats were sacrificed by cervical dislocation and their femurs and tibiae were carefully cleaned from skin by pulling toward the foot, which is cut at the ankle bone. The muscle and connective tissue were removed from both the tibia and the femur by scraping the diaphysis of the bone clean then pulling the tissue toward the ends of the bone. The bones were put in ethyl alcohol $10 \%$ for sterilization and leave it some seconds. The ends of the tibia and femur were cut by sharp Scissors. A 27-gauge needle were Inserted and flushed with Dulbecco's Modified Eagle's Medium DMEM and collect in a $15-\mathrm{ml}$ tube. The cell suspension was filtered through a $70-\mu \mathrm{m}$ filter mesh. BM cells were cultured in DMEM $+10 \%$ FBS $+1 \%$ antibiotic-antimycotic solution (Thermo scientific, USA) in $25 \mathrm{~cm}^{2}$ tissue culture flask and incubated at $37^{\circ} \mathrm{C}$ with $5 \% \mathrm{CO} 2$.

\section{Isolation of Mesenchymal stem cells from Adipose Tissue}

Isolation of MSCs from adipose tissue was performed as previously described (19) with some modifications. The inguinal fat pad was collected under sterile conditions from eight-week-old male Sprague-Dawley rats and washed with phosphate-buffered saline (PBS) containing 1\% antibiotic-antimycotic solution (Thermo scientific, USA). The washing step was repeated until all blood vessels and connective tissues appeared to have been liberated (usually 3 washes).

Adipose tissue sample ( $3 \mathrm{ml}$ for each $1 \mathrm{gm}$ of tissue) was minced into small pieces and digested in $0.1 \%$ Collagenase Type 1 (GIBCO, cat. no. 17100) at $37^{\circ} \mathrm{C}$ with shaking for $2 \mathrm{hr}$. After digestion, an equal volume of DMEM containing $10 \%$ fetal bovine serum (Thermo scientific, USA) was added. For further disintegration of tissue aggregates, the sample was pipetted up and down several times. The cell suspension was filtered through $100 \mu \mathrm{m}$ filter (BD Falcon, USA) for the removal of the solid aggregates. The sample was subsequently centrifuged at $2000 \mathrm{rpm}$ for $5 \mathrm{~min}$ at room temperature and vigorously mixed to complete the separation of the stromal cells from the adipocytes. The centrifugation step was repeated, and the supernatant removed without disturbing the cells. The pellet was re-suspended in $1 \mathrm{ml}$ of lysis buffer (Promega, Germany) to lyse Red Blood Cells, incubated for $10 \mathrm{~min}$, washed with 10 $\mathrm{ml}$ of PBS $+1 \%$ antibiotic-antimycotic mixture and centrifuged at $2000 \mathrm{rpm}$ for $5 \mathrm{~min}$. Supernatant was removed and the cell pellet was re-suspended in complete medium (DMEM with 20\% fetal bovine serum (FBS) and 1\% antibiotic antimycotic solution) in $25 \mathrm{~cm}^{2}$ culture flask and maintained in an incubator supplied with humidified atmosphere of $5 \% \mathrm{CO}_{2}$ at $37^{\circ} \mathrm{C}$.

\section{Cell cultivation}

After 1 day, non-adherent cells were removed by two to three washes with PBS and adherent cells further cultured in complete medium. The medium was changed every 3 days until the monolayer of adherent cells reached 70 80\% confluence. Cell passaging was performed using trypsin-EDTA solution ( $0.25 \%$, Sigma Aldrich, USA). The number of recovered cells evaluated with the use of hemocytometer and cellular viability was quantified by the Trypan Blue exclusion test. Approximatly $250-300 \times 10^{3}$ cells were used to inoculate $75 \mathrm{~cm}^{2}$ culture flask and cultures were incubated at $37^{\circ} \mathrm{C}$ and $5 \% \mathrm{CO}_{2}$. Cell cultivation was performed up to the 3 rd passage.

\section{Flow cytometry analysis}

Cells were characterized using cell surface markers by fluorescence-activated cell sorting (FACS) analysis. The cells were stained with different fluorescently labeled monoclonal antibodies (mAb) (eBioscience, company). In brief, $5 \times 10^{5}$ cells (in $100 \mu 1 \mathrm{PBS} / 0.5 \% \mathrm{BSA} / 2 \mathrm{mmol} / \mathrm{EDTA}$ ) were mixed with $10 \mu \mathrm{l}$ of the fluorescently labeled $\mathrm{mAb}$ (anti-rat CD45-FITC mAb, CD29-PE $\mathrm{mAb}$ and $\mathrm{CD}$ 
90-PCY5) and incubated in the dark at $2 \sim 8^{\circ} \mathrm{C}$ for $30 \mathrm{~min}$. Washing with PBS containing 2\% BSA was done twice and the pellet was re-suspended in PBS and analyzed immediately on EPICS-XL flow cytometer (Coulter, Miami, Fl, USA).

\section{CFU-F assay}

For colony forming unit-fibroblast (CFU-F) assays, about 100 passage- 3 cells were plated in $100-\mathrm{mm}$ tissue culture dish (Falcon) in complete culture medium. Cells were maintained in complete medium for $10 \sim 14 \mathrm{~d}$ at $37^{\circ} \mathrm{C}$ in $5 \%$ humidified $\mathrm{CO}_{2}$, wish half-weekly media changes. On day 14, cells were washed with PBS and fixed in 95\% ethanol for 5 minutes, subsequently, the cells were incubated for 30 minutes at room temperature in $0.5 \%$ crystal violet solution (Sigma Aldrich, USA) in $95 \%$ ethanol. Then the plates were washed twice with distilled $\mathrm{H}_{2} \mathrm{O}$, dried and the resulting CFU-F colonies were counted.

\section{Calculation of population doubling time (PDT)}

PDT is the time by which cell population doubles in number. Population doubling time calculated according to the equation PDT=culture time (CT)/PDN. Population doubling number (PDN) was calculated according to the formulae $\mathrm{PDN}=\log \mathrm{N} / \mathrm{N} 0 \times 3.31$ where $\mathrm{N}$ is the cell number at the end of the cultivation period, N0 the cell number at culture initiation. Cells were plated $10^{4}$ cells $/ \mathrm{cm}^{2}$ in 25 $\mathrm{cm}^{2}$ culture flasks until reaching confluence. Susequently cells were trypsinized and counted; this information is used to calculate PDT.

\section{Growth curve}

To plot the growth curve, passage- 3 cells were plated in 12-well plate at the seeding density of $5 \times 10^{4}$ cells/well and allowed to become confluent. Some wells were trypsinized daily and counted. The growth curve was then plotted using the cell counting data.

\section{BMSCs and ADSCs differentiation capability \\ Osteogenic Differentiation}

Passage 3 MSCs were harvested by trypsin digestion as described above; the cells were counted and seeded at a density of $5 \times 10^{4}$ per well in a 6 -well plate. When $\sim 80 \%$ confluent, osteogenesis differentiation media (DMEM supplemented with 10\% FBS, $0.1 \mu \mathrm{M}$ dexamethasone, $50 \mu \mathrm{M}$ Ascorbic acid, $10 \mathrm{mM} \beta$-glycerol phosphate (Sigma-Aldrich, USA) was added to 4 wells whereas complete culture Media was added to other 2 wells as negative controls. The medium was changed twice per week for $2 \sim 3$ weeks. The differentiation potential for osteogenesis was assessed by
$40 \mathrm{mM}$ Alizarin Red ( $\mathrm{pH}$ 4.1) staining after fixation in $10 \%$ Neutral buffered formalin.

\section{Adipogenic Differentiation}

Passage 3 MSCs were counted and seeded at a density of $\left(10 \times 10^{4}\right.$ per well $)$ in a 6 -well plate. When $\sim 100 \%$ confluent, adipogenesis differentiation media DMEM supplemented with 10\% FBS, $1 \mu \mathrm{M}$ dexamethasone, $500 \mu \mathrm{M}$ isobutylmethylxanthine (IBMX) $5 \mu \mathrm{g} / \mathrm{ml}$ insulin, $200 \mu \mathrm{M}$ Indomethacin (Sigma-Aldrich, USA) was added to 4 wellsand complete culture Media was added to other 2 well as negative controls. The medium was changed twice per week for 2 weeks. The differentiation potential for adipogenesis and formation of intracellular lipid droplets were assessed by Oil-red-O staining after fixation in $10 \%$ Neutral buffered formalin.

Both osteogenic and adipogenic differentiation was analysed digitally: 20 different digital images corresponding to 4 different preparations of differentiated cells and undifferentiated controls were analyzed using ImageJ 1.42 software (U.S. National Institutes of Health http://rsb.Info.nih.gov/ij/) on an appropriate threshold.

\section{Chondrogenic Differentiation}

Passage 3 MSCs were counted and seeded (at a density of $0.25 \times 10^{6}$ per Eppendorf tube) in chondrogenic differentiation medium, which consists of high glucose DMEM supplemented with $10 \mathrm{ng} / \mathrm{ml}$ TGF- $\beta 3,100 \mathrm{n} \mathrm{M} \mathrm{dex-}$ amethasone, $200 \mu \mathrm{M}$ ascorbate 2 phosphate, $40 \mu \mathrm{g} / \mathrm{ml}$ proline, $1 \mathrm{mM}$ pyruvate, $1 \mathrm{mg} / \mathrm{ml} \mathrm{BSA}$ and $50 \mathrm{mg} / \mathrm{ml} \mathrm{ITS}$ +3 . The medium was replaced every $2 \sim 3$ days for 21 days. Production of sulfated glycosaminoglycans was measured in an Alcian blue binding assay (Immunodiagnostic Systems, Boldon, UK) following digestion in $100 \mu 1$ of papain solution. Absorbance was read at $630 \mathrm{~nm}$, as previously described (20).

\section{Results}

\section{Cell culture}

The cultures were observed by using an inverted light microscope. Attachment of spindle-shaped cells to tissue culture plastic flask was observed after 1 day of culture of both BMSCs and ADSCs. Primary cultures reached 70 80\% confluence in approximately 7 9 days for BMSCs and $5 \sim 6$ days for ADSCs. During the passaging, the cell growth tended to accelerate and morphology of cells changed gradually. Cells become more flat-shape with increasing in passage number. After three passages (Fig. 1) both cultures were represented a homogenously fibroblastic cell monolayer. ADSCs showed ability to form multilayer after confluence (Fig. 1E). 

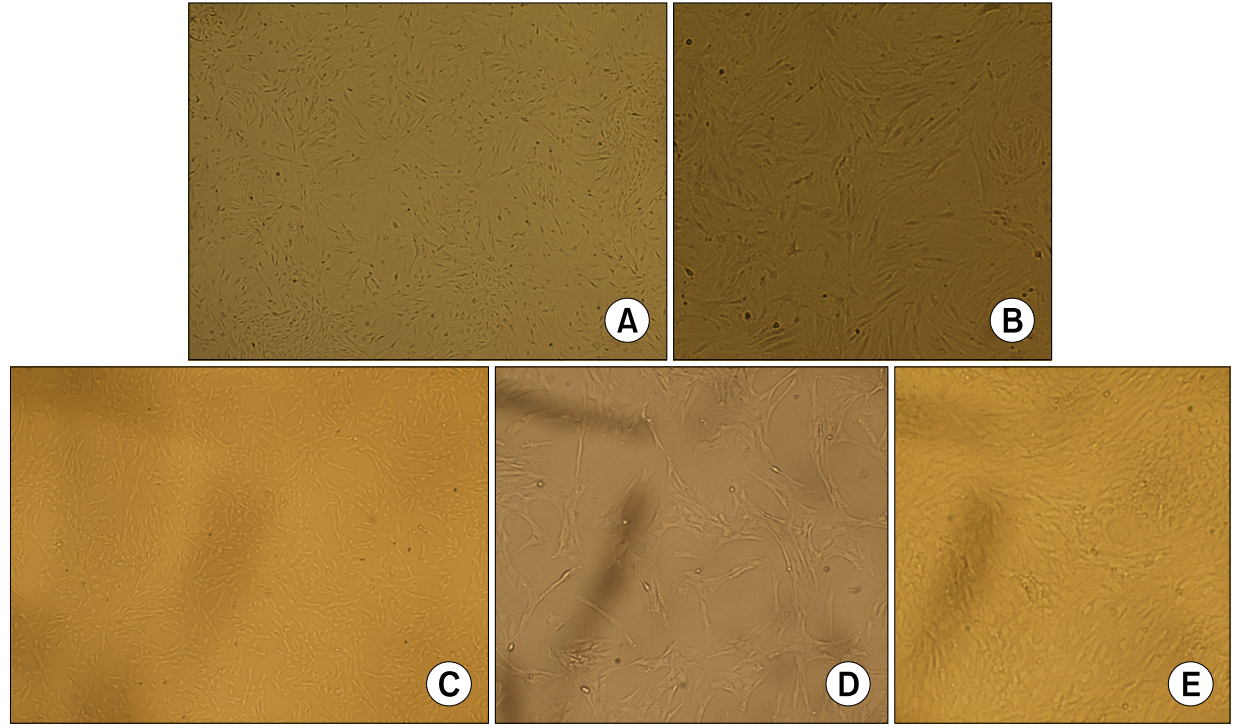

Fig. 1. Image of BMSCs in passage 3 with $80 \%$ confluence (A) $10 \mathrm{X}$ (B) 20X. Image of ADSCs in passage 3 with $80 \%$ confluence (C) 10X. (D) 20X. (E) ADSCs show ability to form multilayer after confluent 20X.

Table 1. Immunophenotypic characterization of BMSCs and ADSCs

\begin{tabular}{|c|c|c|c|c|c|c|c|c|c|}
\hline \multirow{2}{*}{ Antibody } & \multirow{2}{*}{ Conjugate } & \multicolumn{4}{|c|}{ BMSCs\% } & \multicolumn{4}{|c|}{ ADSCs $\%$} \\
\hline & & Sample 1 & Sample 2 & Sample 3 & Mean \pm SD & Sample 1 & Sample 2 & Sample 3 & Mean \pm SD \\
\hline CD90 & PCY5 & 93.9 & 92.9 & 93.8 & $93.5 \pm 0.5$ & 90.7 & 91 & 91.3 & $91 \pm 0.3$ \\
\hline CD29 & PE & 97.8 & 98.6 & 98.4 & $98.2 \pm 0.41$ & 99.5 & 99.8 & 100 & $99.7 \pm 0.25$ \\
\hline CD45 & FITC & 1.53 & 1.73 & 2 & $1.75 \pm 0.23$ & 1.43 & 1.56 & 1.8 & $1.59 \pm 0.18$ \\
\hline
\end{tabular}

\section{Immunophenotypic characterization}

Cultures of third passage BMSCs and ADSCs were analyzed for expression of MSC specific cell-surface markers (21). BMSCs and ADSCs were negative for the hematopoietic lineage marker CD45 with average percentages of $1.75 \pm 0.23$ and $1.59 \pm 0.18$, respectively. BMSCs and ADSCs were positive for CD29 with average percentages of $98.2 \pm 0.41$ and $99.7 \pm 0.25$, respectively. BMSCs and ADSCs were positive for CD90 with average percentages of $93.5 \pm 0.5$ and $91 \pm 0.3$, respectively (Table 1).

\section{CFU-F assay}

CFU-F assay is a suitable tool for evaluating the proliferation and colonogenic capacity of the cells (3th passage) expanded in culture. The colony number of 100 BMSC and ADSCs per 100-mm tissue culture dish was $3 \pm 1.8$ and $37 \pm 1.4$ respectively $(\mathrm{p}<0.05)$. The difference was statistically significant (Fig. 2A).

\section{Population doubling time (PDT)}

The PDT value for ADSCs appeared to be significantly lower than that for the BMSCs indicating the more rapid rate of proliferation of ADSCs. Based on the results, ADSCs tended to double their population in the average of $39.88 \pm 4.4$ hours while those from BMSCs exhibited a doubling time of $49.9 \pm 4.2$ hours $(\mathrm{p}<0.05$ ). (Fig. $2 \mathrm{~B}$ ).

\section{Growth curve}

According to the plotted curve, both BMSCs and ADSCs had no lag phase and started proliferating immediately after being plated. ADSCs had a better proliferation ability than BMSCs. ADSCs unlike BMSCs showed low contact inhibition (Fig. 3C).

\section{Osteogenic differentiation}

BMSCs and ADSCs differentiated into osteoblastic lineage (Fig. 3A and B). Image $\mathrm{J}$ analysis of differentiated vs. undifferentiated cells revealed $4.2 \pm 0.8$ fold increase for and BMSCs 3.4 \pm 0.5 fold increase for ADSCs suggesting BMSCs appeared to have a better ability for osteogenic differentiation.

\section{Adipogenic differentiation}

BMSCs and ADSCs differentiated into adipocyte lineage (Fig. 3C and D). Image $\mathrm{J}$ analysis of differentiated vs. undifferentiated cells revealed $1.2 \pm 0.5$ fold increase for BMSCs $2.6 \pm 0.7$ fold increase for ADSCs. Suggesting ADSCs appeared to have a better ability for adipogenic 
A

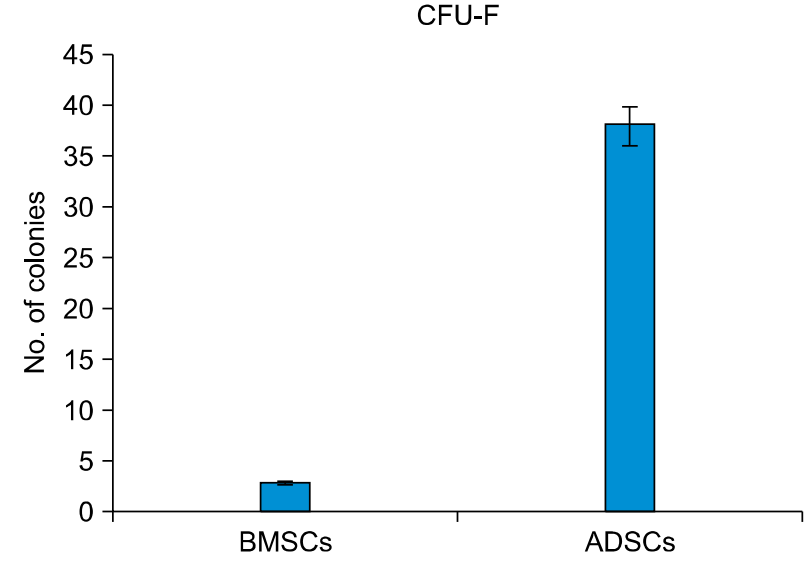

C

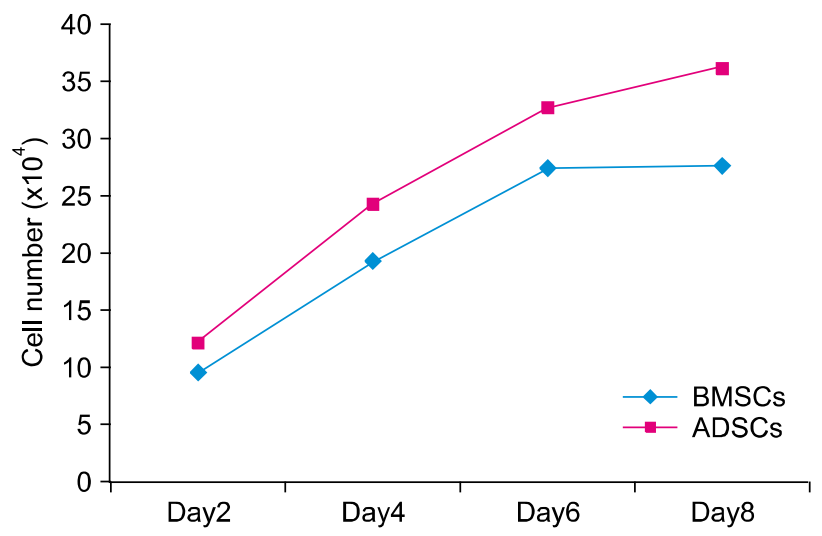

differentiation.

\section{Chondrogenic differentiation}

Both BMSCs and ADSCs differentiated into chondrocytes but BMSCs had more ability to produce sulfated GAG than ADSCs. Concentration of sulfated GAG in BMSC-derived pellets was is $15.95 \mu \mathrm{g} / \mathrm{ml}$ (versus negative control of $3.29 \mu \mathrm{g} / \mathrm{ml})$. Concentration of sulfated GAG in ADSC-derived pellets was $11.66 \mu \mathrm{g} / \mathrm{ml}$ (versus negative control of $0.99 \mu \mathrm{g} / \mathrm{ml}$ ) (Fig. 3E).

\section{Discussion}

This study provides some insights on the differences existing between BMSCs and ADSCs regarding their basic biological properties in vitro. Using such data, investigators will be able to select the right cells for their experimental, preclinical and clinical research.

In the present study, we compared BMSCs with ADSCs from the same species, age and sex (eight-week-old male Sprague-Dawley rat). Young male rats were chosen because experimentally, mesenchymal stem cells were found
B

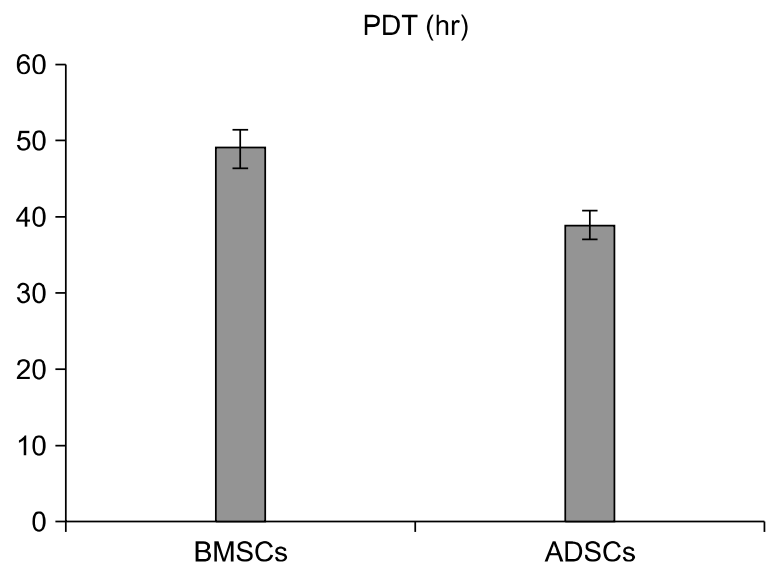

Fig. 2. (A) Number of CFU.F for BMSCs \& ADSCs when plated per 100-mm tissue culture dish. (B) PDT per hours for BMSCs \& ADSCs. (C) Growth curve plotted for BMSCs \& ADSCs.

in larger number in young more than adult and in males more than females $(22,23)$.

Stromal vascular fraction (SVF) was cultured, like bone marrow cells, in DMEM with FBS in plastic flasks. Media of both bone marrow cells and SVF of adipose tissue were changed after 24 hours to get rid of non adherent cells and leave adherent cells which are mostly MSCs. The morphological changes of cells have been noted every day, cells gave spindle shape after about one day and we noticed that cells become more flat-shaped with increasing in passage number. These findings are consistent with the results of Nadri and Soleimani, but their study was on C57BL/6 mouse bone marrow (18). No significant morphologic differences were observed between BMSCs and ADSCs, but BMSCs took longer time than ADSCs to reach $70 \sim 80 \%$ confluence and ADSCs had ability to form multilayer after reaching confluence; this was likely due to low contact inhibition consistent with results of Zhu et al. (24).

Immunophenotyping characterization was performed by flow cytometry. Flow cytometry measurements showed no significant differences between BMSCs and ADSCs, that 

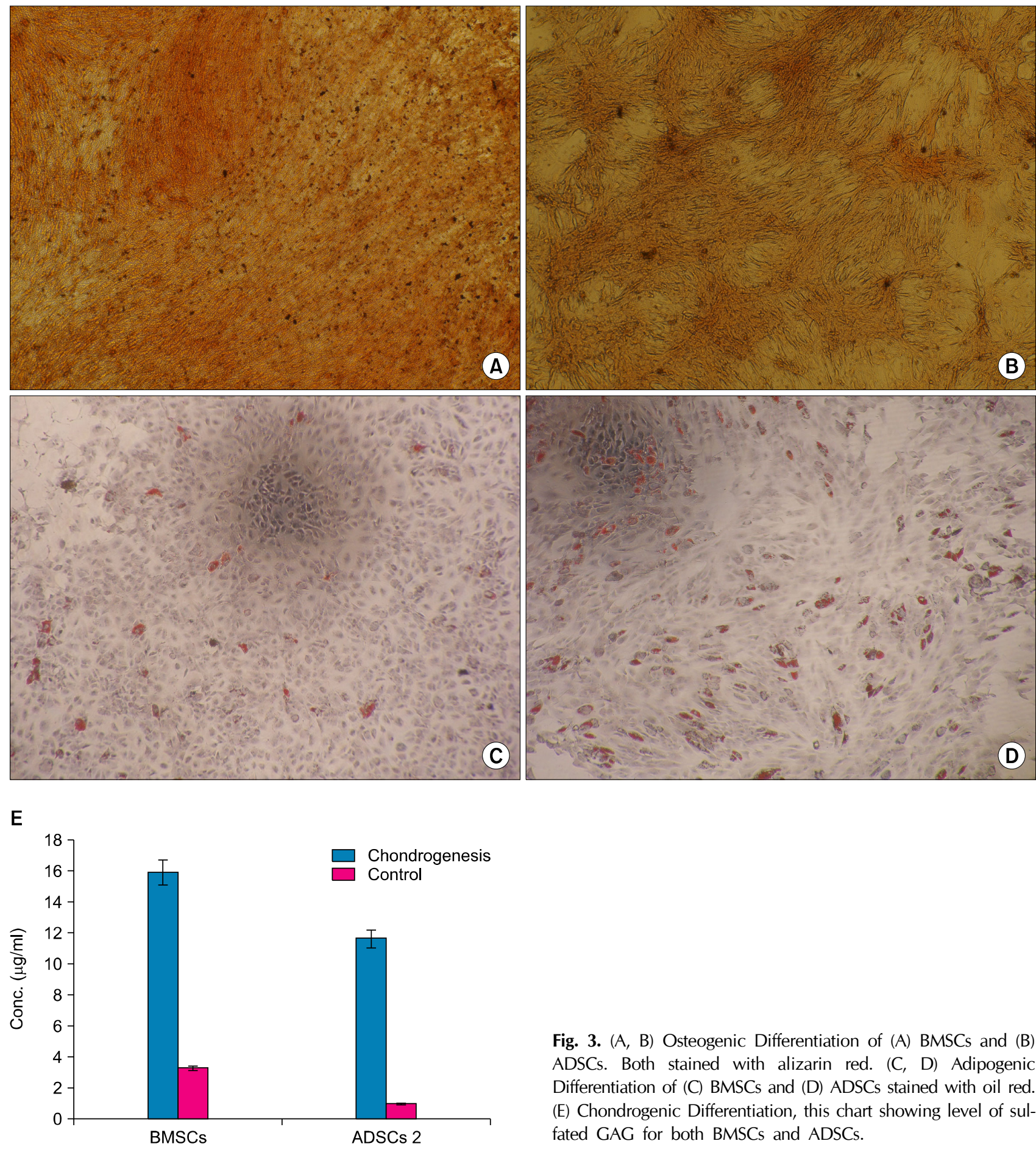

Fig. 3. (A, B) Osteogenic Differentiation of (A) BMSCs and (B) ADSCs. Both stained with alizarin red. (C, D) Adipogenic Differentiation of (C) BMSCs and (D) ADSCs stained with oil red. (E) Chondrogenic Differentiation, this chart showing level of sulfated GAG for both BMSCs and ADSCs.

were both positive for CD29, CD90 and negative for CD45, and these results are consistent with previously published studies $(22,25)$. Colony forming unit-fibroblast (CFU-F) assays were performed to measure the ability of cells for proliferation and clonogenic capacity. Both cell types had an ability to proliferate and form colonies of fibroblasts but ADSCs had better such abilities compared

to BMSCs; these results are consistent with findings of Peng et al. (26).

Population doubling time (PDT) were performed for measuring the time that cells took for doubling their number and BMSCs took longer time for doubling than ADSCs. Growth curve analysis was performed to measure proliferation of cells and phases of their growth through- 
out 8 days. Both BMSCs and ADSCs had no lag phase and started proliferating immediately after being plated but ADSCs had more proliferation ability than BMSCs. ADSCs unlike BMSCs showed low contact inhibition that appeared in the plateau phase. Differentiation capability of BMSCs and ADSCs was tested by placing each cell type cultured in differentiation-induction media compared to control media. Both BMSCs and ADSCs had capability to differentiation to osteoblasts, adipocytes and chondrocytes, however BMSCs appeared to possess better osteogenic and chondrogenic properties compared to ADSCs. On the contrary, in case of adipocyte differentiation, ADSCs appeared to have a better differentiation capability assessed by the amount of fat vacuoles formed in adipocyte differentiated cells. The amount of fat vacuoles in ADSCs adipocyte differentiated cells was higher than that in BMSCs adipocyte differentiated cells and these result are consistent with work of Yoshimura et al. (27) and in contrast to results of Rebelatto et al. (28).

Our results show that both types of cells - BMSCs and ADSCs - have ability for proliferation and the clonogenic capacity. Moreover, we showed that ADSCs are expanding more rapidly than BMSCs. We predict from this in vitro study that ADSCs will be more easily grown than BMSCs in pre-clinical and clinical application. In addition, ADSCs are harvested from patient by a simple and minimally invasive method. This in contrast to Im et al. who casted doubts on the value of adipose tissue as a source of MSCs due to their lower ability for osteogenic differentiation compared with BMSCs (29). On the other hand, our results confirm the findings of Im et al. suggesting that BMSCs may be more efficient than ADSCs in treating bone disease (29).

\section{Conclusion}

The present study compared ADSCs with BMSCs as two different sources for MSCs. Our study showed that, despite many similarities between both types of cells, there are differences existing which can offer assistance on choosing type of cell to be used in specific diseases. Although ADSCs seem more promising for regenerative application generally, BMSCs may represent a better choice for treating bone disorders.

\section{Acknowledgements}

The authors thank Dr.Yasser El Sherbiny for his efforts in the establishment of this collaboration. We are grateful to Dr.Thomas Baboolal and Dr. Richard Cuthbert for their help in stem cells characterization.
This work was supported by Medical Experimental Research Center (MERC), Faculty of Medicine, Mansoura University and Leeds Institute of Rheumatic and Musculoskeletal Medicine, University of Leeds, Leeds, UK.

\section{Potential conflict of interest}

The authors have no conflicting financial interest.

\section{References}

1. Bongso A, Fong C. Human embryonic stem cells: their nature, properties, and uses. In: Baharvand $\mathrm{H}$, editor. Trends in stem cell biology and technology. New York, NY: Humana Press; 2009. 1-18

2. D'Inverno M, Theise N, Prophet J. Mathematical modeling of stem cells: A complexity primer for the stem-cell biologist. In: Potten CS, Clarke RB, Wilson J, Renehan AG, editors. Tissue stem cells. New York: Taylor \& Francis Group; 2006. 1-5

3. Nagy RD, Tsai BM, Wang M, Markel TA, Brown JW, Meldrum DR. Stem cell transplantation as a therapeutic approach to organ failure. J Surg Res 2005;129:152-160

4. Satija NK, Singh VK, Verma YK, Gupta P, Sharma S, Afrin F, Sharma M, Sharma P, Tripathi RP, Gurudutta GU. Mesenchymal stem cell-based therapy: a new paradigm in regenerative medicine. J Cell Mol Med 2009;13:4385-4402

5. Yang KL, Shyr MH. Are Stem Cells the Magical Medical Therapy of the Future? Tzu Chi Med J 2009;21:12-17

6. Liu W, Deng Y, Liu Y, Gong W, Deng W. Stem cell models for drug discovery and toxicology studies. J Biochem Mol Toxicol 2013;27:17-27

7. Jiang Y, Jahagirdar BN, Reinhardt RL, Schwartz RE, Keene CD, Ortiz-Gonzalez XR, Reyes M, Lenvik T, Lund T, Blackstad M, Du J, Aldrich S, Lisberg A, Low WC, Largaespada DA, Verfaillie CM. Pluripotency of mesenchymal stem cells derived from adult marrow. Nature 2002;418:41-49

8. Caplan AI. Adult mesenchymal stem cells for tissue engineering versus regenerative medicine. J Cell Physiol 2007;213:341-347

9. Tae SK, Lee SH, Park JS, Im GI. Mesenchymal stem cells for tissue engineering and regenerative medicine. Biomed Mater 2006;1:63-71

10. Strioga M, Viswanathan S, Darinskas A, Slaby O, Michalek J. Same or not the same? Comparison of adipose tissue-derived versus bone marrow-derived mesenchymal stem and stromal cells. Stem Cells Dev 2012;21:2724-2752

11. Bruno S, Bussolati B. Therapeutic effects of mesenchymal stem cells on renal ischemia-reperfusion injury: a matter of genetic transfer? Stem Cell Res Ther 2013;4:55

12. Mobasheri A, Csaki C, Clutterbuck AL, Rahmanzadeh M, Shakibaei M. Mesenchymal stem cells in connective tissue engineering and regenerative medicine: applications in cartilage repair and osteoarthritis therapy. Histol Histopathol 
2009;24:347-366

13. Reich CM, Raabe O, Wenisch S, Bridger PS, Kramer M, Arnhold S. Isolation, culture and chondrogenic differentiation of canine adipose tissue- and bone marrow-derived mesenchymal stem cells--a comparative study. Vet Res Commun 2012;36:139-148

14. Kisiel AH, McDuffee LA, Masaoud E, Bailey TR, Esparza Gonzalez BP, Nino-Fong R. Isolation, characterization, and in vitro proliferation of canine mesenchymal stem cells derived from bone marrow, adipose tissue, muscle, and periosteum. Am J Vet Res 2012;73:1305-1317

15. Nakanishi C, Nagaya N, Ohnishi S, Yamahara K, Takabatake S, Konno T, Hayashi K, Kawashiri MA, Tsubokawa T, Yamagishi M. Gene and protein expression analysis of mesenchymal stem cells derived from rat adipose tissue and bone marrow. Circ J 2011;75:2260-2268

16. Zhang W, Zhang X, Wang S, Xu L, Zhang M, Wang G, Jin Y, Zhang X, Jiang X. Comparison of the use of adipose tissue-derived and bone marrow-derived stem cells for rapid bone regeneration. J Dent Res 2013;92:1136-1141

17. Melief SM, Zwaginga JJ, Fibbe WE, Roelofs H. Adipose tissue-derived multipotent stromal cells have a higher immunomodulatory capacity than their bone marrow-derived counterparts. Stem Cells Transl Med 2013;2:455-463

18. Nadri S, Soleimani M. Isolation murine mesenchymal stem cells by positive selection. In Vitro Cell Dev Biol Anim 2007; 43:276-282

19. Bunnell BA, Flaat M, Gagliardi C, Patel B, Ripoll C. Adipose-derived stem cells: isolation, expansion and differentiation. Methods 2008;45:115-120

20. Jones EA, English A, Henshaw K, Kinsey SE, Markham AF, Emery P, McGonagle D. Enumeration and phenotypic characterization of synovial fluid multipotential mesenchymal progenitor cells in inflammatory and degenerative arthritis. Arthritis Rheum 2004;50:817-827

21. Boxall SA, Jones E. Markers for characterization of bone marrow multipotential stromal cells. Stem Cells
International 2012;2012:975871

22. Asumda FZ, Chase PB. Age-related changes in rat bone-marrow mesenchymal stem cell plasticity. BMC Cell Biol 2011;12:44

23. Katsara O, Mahaira LG, Iliopoulou EG, Moustaki A, Antsaklis A, Loutradis D, Stefanidis K, Baxevanis CN, Papamichail M, Perez SA. Effects of donor age, gender, and in vitro cellular aging on the phenotypic, functional, and molecular characteristics of mouse bone marrow-derived mesenchymal stem cells. Stem Cells Dev 2011;20:1549-1561

24. Zhu Y, Liu T, Song K, Fan X, Ma X, Cui Z. Adipose-derived stem cell: a better stem cell than BMSC. Cell Biochem Funct 2008;26:664-675

25. Sun CK, Yen CH, Lin YC, Tsai TH, Chang LT, Kao YH, Chua S, Fu M, Ko SF, Leu S, Yip HK. Autologous transplantation of adipose-derived mesenchymal stem cells markedly reduced acute ischemia-reperfusion lung injury in a rodent model. J Transl Med 2011;9:118

26. Peng L, Jia Z, Yin X, Zhang X, Liu Y, Chen P, Ma K, Zhou C. Comparative analysis of mesenchymal stem cells from bone marrow, cartilage, and adipose tissue. Stem Cells Dev 2008;17:761-773

27. Yoshimura H, Muneta T, Nimura A, Yokoyama A, Koga H, Sekiya I. Comparison of rat mesenchymal stem cells derived from bone marrow, synovium, periosteum, adipose tissue, and muscle. Cell Tissue Res 2007;327:449-462

28. Rebelatto CK, Aguiar AM, Moretão MP, Senegaglia AC, Hansen P, Barchiki F, Oliveira J, Martins J, Kuligovski C, Mansur F, Christofis A, Amaral VF, Brofman PS, Goldenberg S, Nakao LS, Correa A. Dissimilar differentiation of mesenchymal stem cells from bone marrow, umbilical cord blood, and adipose tissue. Exp Biol Med (Maywood) 2008;233:901-913

29. Im GI, Shin YW, Lee KB. Do adipose tissue-derived mesenchymal stem cells have the same osteogenic and chondrogenic potential as bone marrow-derived cells? Osteoarthritis Cartilage 2005;13:845-853 